\title{
Russian Arctic region energy balance (Republic of Sakha (Yakutia))
}

\author{
Vasiliy Zakharov, Dmitry Prokhorov, and Nikita Pavlov \\ IPTPN SB RAS, Energy Problems Department, 677980 Yakutsk, Oktyabrskaya st., 1, Russian Federation
}

\begin{abstract}
The Arctic territories have a low population density due to the severity of the climate. Nevertheless, the indigenous people have been living in the Arctic for centuries. Ensuring their energy security is a complex technical task and at the same time is one of the significant costs of regional state budgets. The article analyzes the energy balance of the Arctic administrative regions of the largest region of the Russian Federation - the Republic of Sakha (Yakutia). Potential optimization of energy balance while maintaining the existing technological platform.
\end{abstract}

\section{Introduction}

The Arctic is the most important part of the Russian Federation. Interest and claims to the Arctic resources and territories have other states too. The interaction of states in the Arctic is regulated by documents of international law and treaties between individual states. These documents are valid only when maintaining the balance of power in the world at the time of their signing. The Russian Arctic is not an empty territory, recorded only by the military presence. The Russian Arctic is inhabited. This is the original habitat of many peoples - citizens the Russian Federation [1-5].

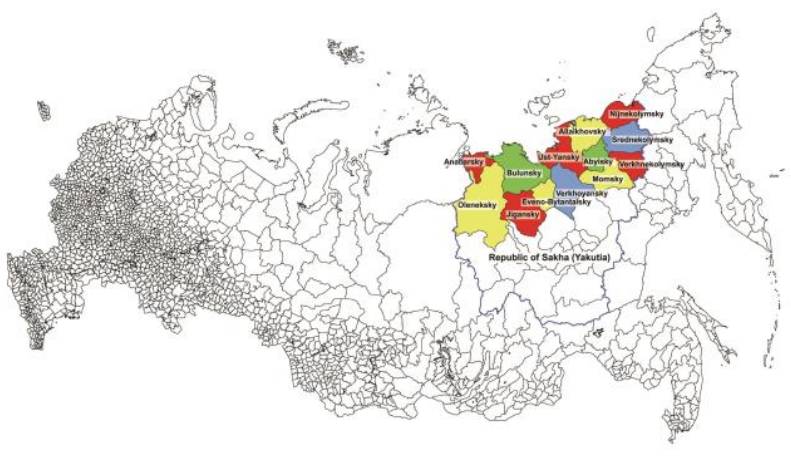

Fig. 1. The map of Arctic districts of Republic of Sakha (Yakutia).

The Republic of Sakha is the largest region of the Russian Federation (Figure 1). Almost half of the territory belongs to the Arctic zone. There are 13 administrative districts here. About 70 thousand people live here. The industry here is underdeveloped. The energy system provides the needs of the local population. The article describes the change in the energy balance of the Arctic of Republic of Sakha in 2012-2017. The priorities of the development of the energy infrastructure of the Arctic regions of the republic are given.

\section{Actual energy balance}

\subsection{Primary energy resources consumption}

In the reporting period, the share of coal in the consumption structure increased by $15 \%$, oil and gas condensate decreased by $6 \%$ and $2 \%$, respectively (Figure 2). The use of firewood in centralized heating systems is practically excluded. The share of firewood in the fuel balance in 2017 is only about $2 \%$. Until 2012, diesel fuel boilers operated. In 2017, diesel fuel in the boiler is not burned. Diesel fuel is consumed to produce electricity. Other fuels are consumed to generate heat.

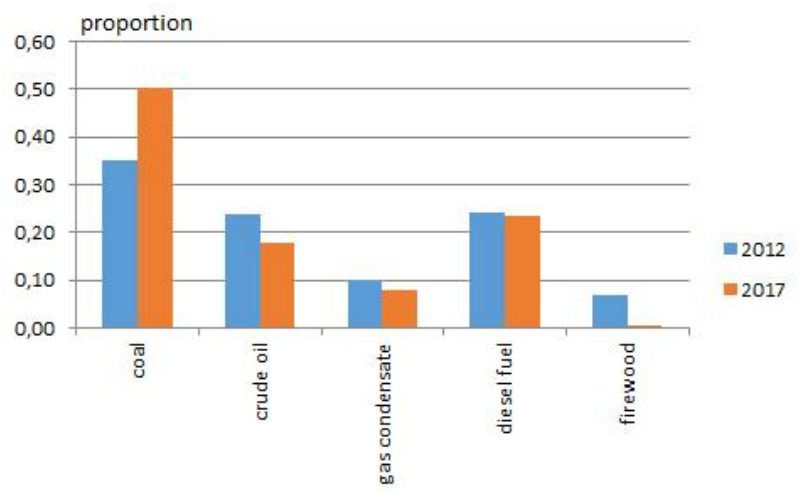

Fig. 2. Changes in primary energy consumption in the Republic of Sakha Arctics ${ }^{\mathrm{a}}$.

\subsection{Electricity and heat production}

\footnotetext{
${ }^{a}$ Based on information from the Federal Statistical Service
} 
Heat production increased by 8,53\%. Electricity production - by $9,91 \%$ (Figure 3 ). The main increase in the production of electricity occurred in the Bulunsky district. Electricity production grew by $67 \%$ here. The change in heat production is within the normal fluctuation.

The main amount of fuel consumed in winter. During this period, the potential of renewable energy sources (solar and wind) reaches a minimum too. Therefore, they do not yet have a significant share in the generation of electricity and heat. In 2017, the share of electricity generation from renewable sources was $0.35 \%$.

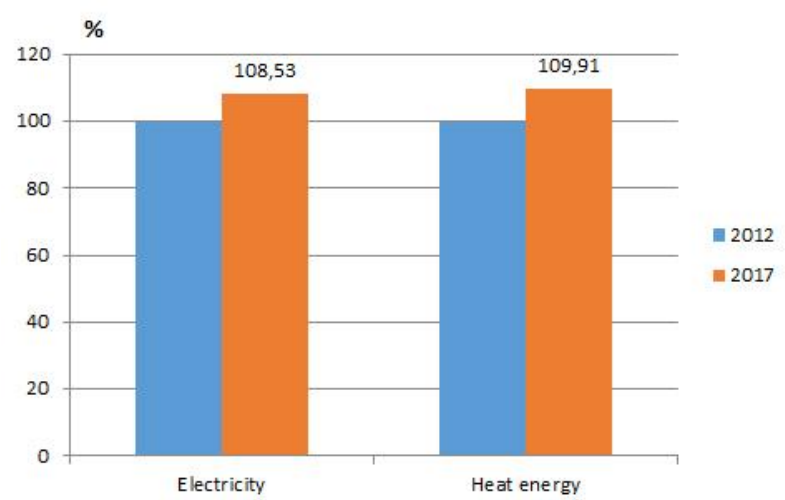

Fig. 3. Changes in the production of electricity and heat.

\subsection{Fuel efficiency}

Fuel efficiency in the generation of final types of energy has increased. In electric power industry, it rose by $2 \%$, in heat supply - by $5 \%$ (Figure 4 ). Electricity generation efficiency is almost at the limit of the technological capabilities of diesel engine base power plant. Heat generation still has significant improvement potential. Small boilers on ordinary coal reduce the total efficiency of heat production

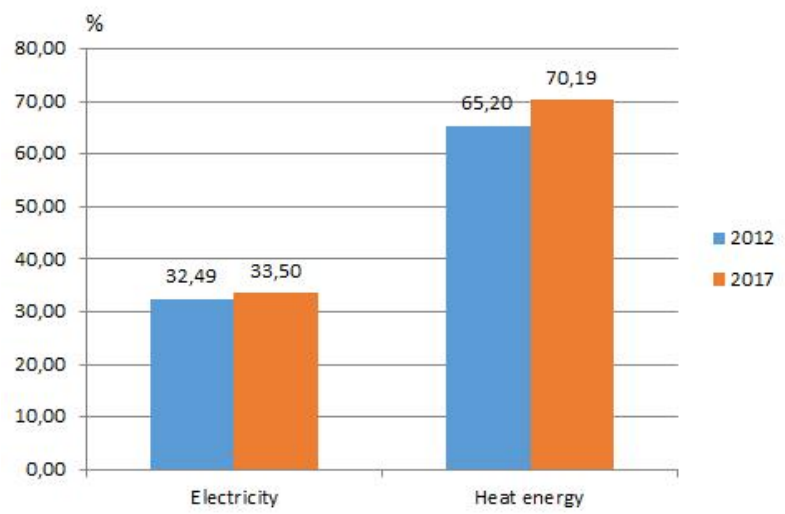

Fig. 4. Fuel efficiency in the production of electricity and heat, percentage.

Over the given period, the efficiency of use of diesel fuel has noticeably increased in Zhigansky, Momsky and Nizhnekolymsky districts (Figure 5). Most local diesel power plants have an efficiency of 30 percent.

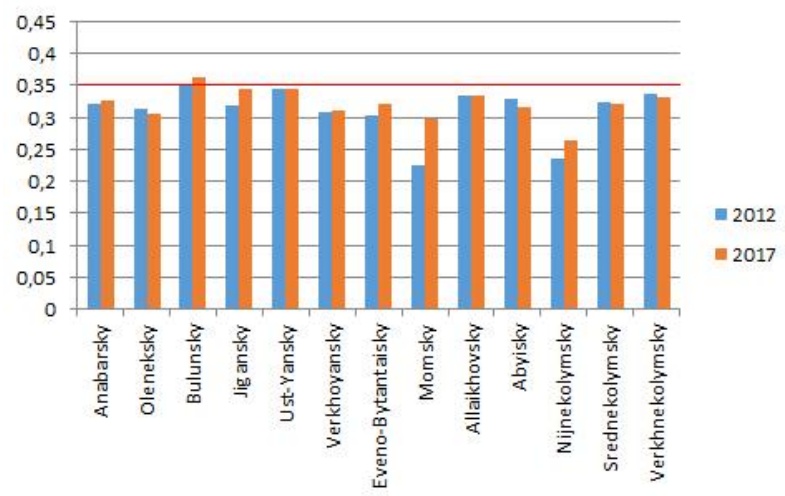

Fig.5. Fuel efficiency in the production of electricity by district, share.

The quality of information about the heat supply sector is much worse than about the power supply sphere. This is due to the lack of heat metering devices by many consumers and suppliers of heat. Also plays a role the lack of an accurate accounting system of coal consumed. High fuel efficiency use have heat systems on liquid hydrocarbon fuel (crude oil, gas condensate). The fuel efficiency of energy systems cannot fundamentally exceed the efficiency of power plants. Accordingly, the initial data of the Bulunsky district are of low quality (Figure 6). The increase in efficiency in Momsky and Eveno-Bytantaysky districts was due to the displacement of firewood by crude oil. In Ust-Yansky district, partial replacement of raw coal with crude oil was also carried out.

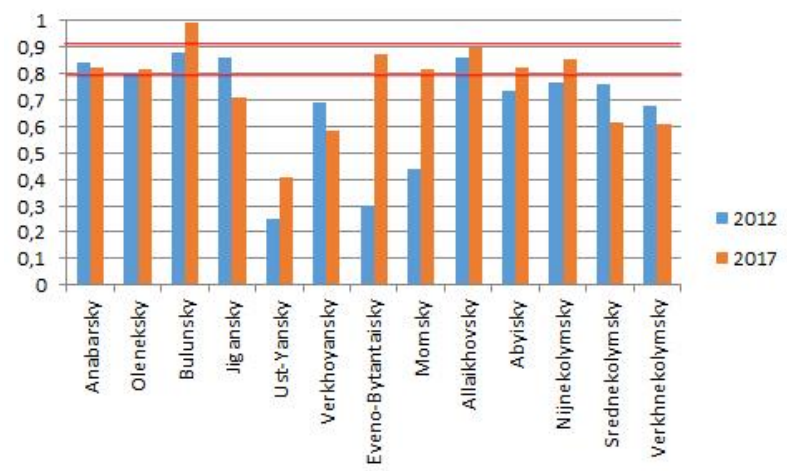

Fig.6. Fuel efficiency in the production of heat by district, share.

\section{Energy balance optimization potential}

The potential for optimizing the energy balance primarily consists in bringing fuel efficiency to the technological limits of the efficiency of power plants. The technological limit of efficiency of diesel power plants is estimated at 35\% (Figure 5). The technological limit of efficiency of boiler houses on liquid fuel is $90 \%$. The same parameter for coal-fired boilers is $80 \%$ (Figure 6 ). The coal delivery scheme also has the potential for optimization. On delivery, $4-10 \%$ of coal is lost. Due to the duration of delivery there is a decrease in the quality of coal [6-10]. 
The decrease in coal quality is primarily due to oxidation processes. A significant effect is the change in moisture content of coal. Based on the results of studies conducted in IPTPN SB RAS, the change in the moisture content of coal is cyclical [11]. Cycles correlate with the seasons of the year. In the cold season from September to March, the process of evaporation of moisture slows down significantly and moisture accumulates. In January-December, when the peak of consumption is reached, coal enters boiler rooms with maximum humidity. Since March, the processes of evaporation of moisture again begin to increase. The processes of coal oxidation also correlate with the seasons of the year. But this process goes with accumulation. A significant decrease in the oxidation rate during the cold season has been recorded. Explained by some researchers, the reduction of the reaction area of coal due to the coating of an ice crust. With the onset of spring, the reaction area increases due to the opening of cracks and pores formed by ice [12-13].

Optimization of the energy balance requires solving the problem of accounting for the consumed and moved volumes of fuel. Currently, a satisfactory metering system operates only for liquid fuels. There is no complete accounting system for coal. In water transport, accounting is conducted conditionally on the draft of ships. In intermediate and consumable warehouses, the amount of coal is measured by surveying methods. Due to the complex topography of warehouses and deep snow cover, the accuracy of these methods is very low. Energy companies are trying to solve these problems by building stationary automotive weighing equipment at intermediate and waste storage facilities. This approach has unacceptably high costs. An alternative solution could be supplying the Arctic regions with coal packed in FIBC. Packing of coal in big bags is able to solve additionally the problem of preserving the quality of coal during long-term storage. The introduction of packaging can begin with small batches. Changes to the existing transport infrastructure will be minimal. According to the calculations of the IPTPN SB RAS, the cost of the most expensive FIBC packing is 2-3 times less than the cost of loss of the energy value of coal when it is shipped to the Arctic regions [8].

The development potential of renewable energy sources is currently difficult to determine. On the one hand, the annual arrival of solar radiation in the Arctic regions is the largest compared to other Arctic territories of Russia, on the other hand, the main consumption of power and electricity falls in the winter months, when electricity generation by solar panels is minimal. Apparently, in the near future, the development of solar generation will focus on the maximum summer load, which is 4-5 times lower than the winter load. The economically payable capacity of a solar power plant with existing technologies can save up to $10 \%$ of the annual consumption of diesel fuel in the Arctic settlements. Table 1 shows the calculation of the proportion of the saved volume of diesel fuel caused by the operation of solar power plants in the Arctic zone of the Republic of Sakha in 2017. Solar generation can achieve a significant share in the energy balance during the technological breakthrough in seasonal energy storage. Hydropower potential for energy supply of Arctic settlements is low. This is because of most settlements in the Arctic are far from the mountain rivers and situated mostly on the plains. Technological difficulties also form the water regime of the northern rivers. In winter, water consumption drops sharply. But determining the location of small hydroelectric power plants in the Arctic is also important and extremely necessary nowadays. The possibilities of using wind and solar energy in centralized heating systems have not been thoroughly studied.

Table 1. Share of annual diesel fuel savings due to the operation of solar power plants in $2017, \%^{\mathrm{b}}$

\begin{tabular}{|c|c|c|}
\hline Solar Plant & District & $\begin{array}{c}\text { Annual diesel } \\
\text { savings, \% }\end{array}$ \\
\hline Dulgalakh $20 \mathrm{~kW}$ & Verkhoyansky & 6,457 \\
\hline Eyik $40 \mathrm{~kW}$ & Oleneksky & 4,099 \\
\hline Kebergene $20 \mathrm{~kW}$ & Abyisky & 2,425 \\
\hline Jargalakh $15 \mathrm{~kW}$ & Eveno-Bytantaisky & 5,428 \\
\hline Yunkyur $40 \mathrm{~kW}$ & Verkhoyansky & 3,885 \\
\hline Betenkes $40 \mathrm{~kW}$ & Verkhoyansky & 3,894 \\
\hline Stolby $10 \mathrm{~kW}$ & Verkhoyansky & 1,918 \\
\hline
\end{tabular}

Losses in district heating networks average $20 \%$. Heat losses through the enclosing structures of residential and administrative buildings were not evaluated by anyone. Due to the high proportion of old wooden houses, the potential for energy savings in the residential sector can be significant. Only the owners themselves can realize the energy saving potential of residential buildings.

According to the authors, there is a significant potential in terms of electricity consumption. In the arctic regions, there is a widespread consumption of electricity for heating needs in the summer period and as an additional source of heat in winter. One of the ways to use solar energy to heating purposes is using solar collectors with solar concentrating systems in summer time. On energy savings, there are hopes for smart grid technology. As part of smart grid solutions, there are fundamental opportunities to smooth daily load schedules and improve the performance of power plants.

The possibilities of reducing fuel consumption with the existing technological platform are shown in Figure 7. Under the existing power supply system, the consumption of all fuel can be reduced by 42 percent.

${ }^{\mathrm{b}}$ Annual Report of Sakhaenergo JSC for 2017 


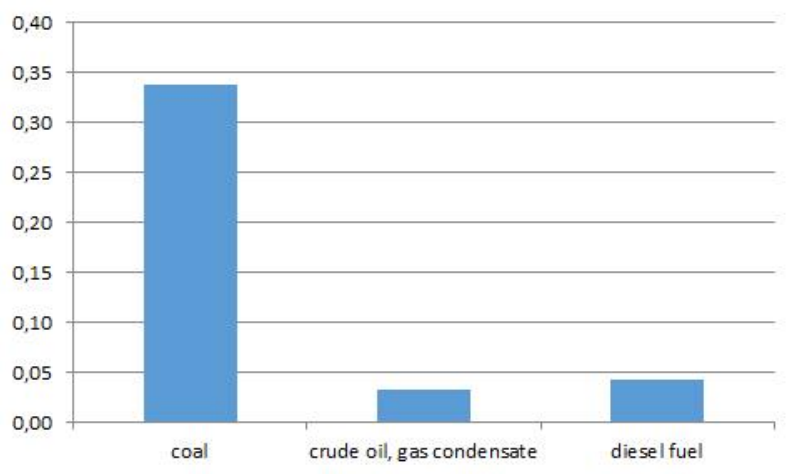

Fig.7. Potential to reduce the consumption of primary energy resources, share.

\section{Conclusion}

The article presents the energy balance of the Arctic administrative regions of the Republic of Sakha (Yakutia). In the short term, there is a huge potential to reduce coal losses. The primary task is to ensure the stability of the quality of coal and the elimination of losses during transportation. Improving the efficiency of boiler rooms is more expedient to carry out the second step focusing on high-quality varietal coal.

The Republic is the most difficult region in terms of ensuring energy security. This is due to the lack of yearround transport infrastructure. In the existing economic paradigm, the development of transport infrastructure is possible only with the development of natural resources. Fuel delivery is a complex logistic operation. The success of the operation depends on the climatic conditions. Providing long-term guarantees of energy security in the region is almost impossible. The only way out is to reserve funds for the possible delivery of fuel on winter roads in case of a frustration of the delivery plan by waterways. Optimization of the energy balance is the main tool for analyzing ways to reduce the necessary reserve funds. The prospective structure of the energy balance depends on the financial capacity of the regional budget. Public participation in this is limited due to government regulation of tariffs. Energy supplying enterprises also have no incentive to optimize also due to government guarantees of normalized profit. Consequently, de facto optimization of the fuel and energy balance has become the task of the regional government. If, as part of the improvement of the existing technological platform, the capabilities of the tariff tool remain, then the introduction of elements of a new technological platform requires budget investments.

\section{References}

1. The Constitution of the Russian Federation (as amended on 21 July 2014).

2. The strategy for the development of the Arctic zone of the Russian Federation and national security for the period up to 2020 .

3. The Federal Law "About the territories of traditional nature use of indigenous peoples of the North, Siberia and the Far East of the Russian Federation" dated May 7, 2001 N 49-FZ

4. Borisov E., Galichanin E., Uvarov V. Northeast of Russia: regional economy and management. (Fintrex, 2006) (in Russian).

5. V. Mikhailov, A. Chukin. Indigenous peoples of the Far East, (1999) (in Russian).

6. Decree of the Government of the Republic of Sakha (Yakutia) "On approval of consumption standards for fuel and energy resources for heat generation by heating and production boilers of the Republic of Sakha (Yakutia)" dated July 14, 2005 No. 433.

7. V. Zakharov. Features of the transport system of the Republic of Sakha (Yakutia) and the substantiation of the need for searching of ways to increase the reliability of coal supply.E3S Web of Conferences 77, 04001 (2019) «Regional Energy Policy of Asian Russia 2018". DOI 20197704001.

8. V. Zakharov. Ways to improve the methods of recording the volume of stored coal in the supply of hard-to-reach consumers. «Eurastrencold - 2018». (2018) (in Russian).

9. V. Gavrilov, V. Fedorov, V. Zakharov. Reserves to reduce coal losses while ensuring the northern regions of Yakutia. Actual problems, directions and mechanisms of development of the productive forces of the North 2016: Materials of the Fifth All-Russian Scientific Seminar (2016) (in Russian)

10. V. Zakharov, D. Prokhorov, V. Gavrilov Losses of the energy value of raw coal upon delivery to Arctic consumers of the Republic of Sakha (Yakutia) «Izvestiya vuzov. Energy problems», 5-6, (2013). (in Russian).

11. V. Zakharov, A. Kozlov, I. Donskoy "Modeling the change in the heat of combustion of coal during transportation to the regions of the Far North, on the example of the Republic of Sakha (Yakutia)" "Izvestiya RAN. Energetika», 6, (2018) DOI: 10.31857/S000233100003526-2.

12. S. Fedorova, Prevention of spontaneous combustion of coal in permafrost. GIAB, 12 (2003).

13. P. Vasiliev Control and prevention of spontaneous combustion of permafrost coals. GIAB. 8 (2001). 